Research Article

\title{
Evaluation of modified Alvarado scoring system in diagnosis of acute appendicitis - a prospective study
}

\author{
Vishad Patel*, Manoj Kela, Sanjay Prasad, Ajeet Singh Gautam, Mohit Gupta
}

Department of Surgery, SAMC PGI, Indore, M.P., India

Received: 05 January 2016

Accepted: 04 February 2016

\author{
*Correspondence: \\ Dr. Vishad Patel, \\ E-mail: drvishad84@gmail.com
}

Copyright: () the author(s), publisher and licensee Medip Academy. This is an open-access article distributed under the terms of the Creative Commons Attribution Non-Commercial License, which permits unrestricted non-commercial use, distribution, and reproduction in any medium, provided the original work is properly cited.

\begin{abstract}
Background: The most frequently encountered complaint which is a surgical emergency also is pain in abdomen and under this spectrum falls pain of acute appendicitis, which remains very common cause of acute surgical abdomen. The diagnosis may be straightforward or tricky due to variable clinical presentations. Emergency appendectomy is usually done on decision taken by surgeon.

Methods: It includes all patients admitted for pain in the right iliac fossa with provisional diagnosis of Acute appendicitis and treated at SAMC PGI, including all patients above the age of 16 years admitted with pain in the right iliac fossa with provisional diagnosis of Acute Appendicitis and excluding those with severe cardiac risk for surgery, associated malignancy or with associated ascites.

Results: A total of 95 patients were included in our study out of which 9 patients were diagnosed with different pathology than appendicitis. Out of 86 confirmed with appendicitis $69.76 \%$ were male and $30.24 \%$ were female. Maximum incidence in adult age group seen in 20-40 years (67\%).Incidence after 50 years of age is very less $(4.65 \%)$ In our study out of 51 modified Alvarado score positive cases, $49(96 \%)$ were histologically positive and $2(4 \%)$ were negative. Whereas among remaining 35 modified Alvarado score negative cases only $20(57.14 \%)$ were histologically positive with a $\mathrm{p}$ value $<0.0001$. Among the 68 ultrasonography positive cases for appendicitis, $65(95.5 \%)$ were also found to have positive features of appendicitis on histopathologically examination and out of them 3 (4.4\%) were histologically negative.

Conclusions: Acute appendicitis is one of the most common acute abdominal conditions requiring emergency surgery and its diagnosis remains challenging. Thus we finally conclude that incorporation of modified Alvarado scoring system for establishment of diagnosis in cases of suspected acute appendicitis surely provides higher accuracy of diagnosing acute appendicitis and helps in decreasing negative appendectomies.
\end{abstract}

Keywords: Modified alvarado score, Usg - ultrasonography

\section{INTRODUCTION}

For a surgeon, the most frequently encountered complaint which is a surgical emergency also, is pain in abdomen and under this spectrum falls pain of acute appendicitis, which remains very common cause of acute surgical abdomen. ${ }^{1}$

The diagnosis may be straightforward or tricky due to variable clinical presentations. Emergency appendectomy is usually done on decision taken by surgeon. Despite of modern diagnostic aids diagnosis of acute appendicitis is mostly clinical. A wrongly made diagnosis is responsible for significant mortality and morbidity. Diagnostic difficulties in cases with atypical clinical finding have resulted in high rate of negative appendectomies, which have been reported variably between $15-30 \%$. The prime goal of surgeon is removal of inflamed appendix before perforation with minimal negative appendectomies. ${ }^{2,3}$

Thus this arises need of a method, which can complement clinical diagnosis and make clinical decision more 
precise and consistent. Diagnostic scoring systems are useful and easy methods that help us in arriving at a surgical decision. Presently various diagnostic scoring systems have been proposed to abet diagnosis of acute appendicitis. One of them is modified Alvarado scoring system that has enhanced our ability to diagnose a case of acute appendicitis.

\section{METHODS}

\section{Source of data}

- It includes all patients admitted for pain in the right iliac fossa with provisional diagnosis of acute appendicitis and treated at SAMC PGI.

- A Performa drafted for the study of all patients with pain in the right iliac fossa will be used. Evaluation will be done by history, clinical features (Variables of Modified Alvarado score); and special tests if any required.

- All cases admitted during the period from November 2013 to May 2015 were included in the study.

\section{Inclusion criteria}

- All patients above the age of 16 years admitted with pain in the right iliac fossa with provisional diagnosis of Acute Appendicitis.

\section{Exclusion criteria}

- All patients with severe cardiac risk for surgery.

- Patients with associated malignancy.

- Patients with associated ascites.

\section{Method of collection of data}

It is a prospective study conducted on patients who were suspicious for acute appendicitis were admitted and examined by consultants of SAMC, PGI. Patients underwent thorough clinical examination, routine preoperative investigations and ultrasonography. Patients were also allotted MAS (modified Alvarado score) depending on clinical findings and investigations which is as followed.

Table 1: Modified Alvarado score depending on clinical findings and investigations.

\begin{tabular}{|ll|}
\hline Modified Alvarado score & Score \\
\hline Symptoms & \\
\hline Migratory Rt. Iliac fossa pain & 1 \\
\hline Anorexia & 1 \\
\hline Nausea/Vomiting & 1 \\
\hline Signs & \\
\hline Tenderness Rt. Lower quad. & 2 \\
\hline Rebound Tenderness Rt. Iliac Fossa & 1 \\
\hline Pyrexia $>37.30 \mathrm{C}$ & 1 \\
\hline Investigations & \\
\hline Leucocytosis $>10 \mathrm{X} 10^{9} / \mathrm{L}$ & 2 \\
\hline Total & 9 \\
\hline
\end{tabular}

Modified Alvarado score more than or equal to 7 was considered positive for appendicitis while score equal to or less than 6 was considered negative. Preoperative ultrasonography was done for all patients and two groups were made on the basis of positive or negative finding of acute appendicitis in ultrasonography.

Postoperatively specimen of appendix was sent for histopathological examination and reports were noted. It was considered as gold standard for diagnosis. The MAS and ultrasonography findings were then compared to histopathology report.

When a positive modified alvarado score case has positive histopathologically report, the cases are considered as true positive and the histologically negative cases among modified alvarado score negative cases are considered as true negative. Histologically negative cases among modified alvarado score positive cases are false positive and histologically positive cases among modified alvarado score negative are false negative cases.

From above data sensitivity, specificity, positive predictive value, diagnostic accuracy false negative rates are calculated. When ultrasonographically positive cases have histopathologically positive report, the cases are true positive and the ultrasonography negative cases with histologically negative cases are considered as true negative.

Histopathologically negative cases among ultrasonography positively cases are false positive cases and histologically positive cases among ultrasonography negative cases are false negative cases. From above data the sensitivity, specificity positive predictive value, diagnostic accuracy false negative rate are calculated and then compared with that of modified alvarado score data.

\section{RESULTS}

A total of 95 patients were included in our study out of which 9 patients were diagnosed with different pathology than appendicitis.

Table 1: Distribution of patients.

\begin{tabular}{|l|l|}
\hline & No. of Patients \\
\hline Total Patients & 95 \\
\hline Diagnosed with Appendicites & 86 \\
\hline
\end{tabular}

In our study a total of 95 patients were included, out of which 86 were confirmed with appendicitis while remaining 9 were diagnosed with other pathology.

Table 2: Sex distribution.

\begin{tabular}{|lll|}
\hline Gender & No. of patients & Percentage \\
\hline Male & 60 & 69.76 \\
\hline Female & 26 & 30.24 \\
\hline
\end{tabular}


Out of 86 confirmed with appendicitis $69.76 \%$ were male and $30.24 \%$ were female.

Table 3: Age distribution.

\begin{tabular}{|lll|}
\hline Age (Years) & No. of patients & Percentage \\
\hline$<20$ & 6 & 6.90 \\
\hline $20-30$ & 30 & 34.88 \\
\hline $31-40$ & 28 & 32.55 \\
\hline $41-50$ & 18 & 20.93 \\
\hline$>50$ & 4 & 4.65 \\
\hline
\end{tabular}

The maximum incidence of appendicitis among adult age group was found to be in the age group of 20-40 years with a total percentage of $67.43 \%$ \& least in above 50 years age group with a mere percentage of $4.65 \%$.

Table 4: Modified Alvarado score.

\begin{tabular}{|lll|}
\hline Modified alvarado score & $\begin{array}{l}\text { No. of } \\
\text { patients }\end{array}$ & Percentage \\
\hline$\leq 6$ (Negative) & 35 & 40.7 \\
\hline$\leq 7$ (Positive) & 51 & 59.3 \\
\hline
\end{tabular}

Out of 95 patients, 86 were confirmed to be appendicitis and Modified Alvarado score was applied to them, which showed $59.3 \%$ were positive and $40.7 \%$ were negative.

Table 5: Histopathological findings.

\begin{tabular}{|lll|}
\hline $\begin{array}{l}\text { Histopathological } \\
\text { findings }\end{array}$ & $\begin{array}{l}\text { No. of } \\
\text { patients }\end{array}$ & Percentage \\
\hline Positive & 69 & 80.3 \\
\hline Negative & 17 & 19.7 \\
\hline
\end{tabular}

Out of the 86 patient's undergone appendectomy, $80.3 \%$ were histologically positive for acute appendicitis and 19.7 were histologically negative.

Table 6: Comparison between modified Alvarado Score and histopathological findings.

\begin{tabular}{|lllll|}
\hline \multirow{2}{*}{$\begin{array}{l}\text { Modified Alvarado } \\
\text { Score }\end{array}$} & \multicolumn{3}{l}{ Histopathological findings } \\
\hline & Positive & Negative \\
\hline$\geq$ (Positive) & No. & $\%$ & No. & $\%$ \\
\hline$\leq$ (Negative) & 49 & $96 \%$ & 2 & $4 \%$ \\
\hline P & 20 & $57.14 \%$ & 15 & $42.9 \%$ \\
\hline
\end{tabular}

$\mathrm{P}$ value $<0.0001$

In our study out of 51 modified alvarado score positive cases, 49 (96\%) were histologically positive and $2(4 \%)$ were negative, whereas in the remaining 35 modified alvarado score negative cases 20 (57.14\%) were histologically positive.

In the present study modified alvarado score had a sensitivity of $71.01 \%$, specificity of $88.2 \%$, positive predictive value of $96.07 \%$, negative predictive value of
$42.85 \%$, diagnostic accuracy of $74.41 \%$, false positive error rate of $11.76 \%$ and a false negative error rate of $28.98 \%$.

Table 7: Analysis of modified Alvarado score in diagnosing acute appendicitis (histopathological findings being gold standard).

\begin{tabular}{|ll|}
\hline Modified Alvarado Scoring System & Percentage \\
\hline Sensitivity & $71.01 \%$ \\
\hline Specificity & $88.2 \%$ \\
\hline Positive predictive value & $96.07 \%$ \\
\hline Negative predictive value & $42.85 \%$ \\
\hline Diagnostic accuracy & $74.41 \%$ \\
\hline False positive error rate & $11.76 \%$ \\
\hline False negative error rate & $28.98 \%$ \\
\hline
\end{tabular}

Table 8: Ultrasonography.

\begin{tabular}{|lll|}
\hline Ultrasonography & No. of Patients & Percentage \\
\hline Positive & 68 & $79.06 \%$ \\
\hline Negative & 18 & $20.94 \%$ \\
\hline
\end{tabular}

Out of 86 cases, $68(79.06 \%)$ were positive for acute appendicitis on ultrasonography, while 18 (20.94\%) were negative.

Table 9: Comparison between ultrasonography and histopathological findings.

\begin{tabular}{|lllll|}
\hline \multirow{2}{*}{ Ultrasonography } & \multicolumn{3}{l}{ Histopathological findings } \\
\cline { 2 - 5 } & \multicolumn{2}{l|}{ Positive } & \multicolumn{2}{l|}{ Negative } \\
\cline { 2 - 5 } & No. & $\%$ & No. & $\%$ \\
\hline Positive & 65 & $95.5 \%$ & 3 & $4.4 \%$ \\
\hline Negative & 4 & $22.22 \%$ & 14 & $77.77 \%$ \\
\hline
\end{tabular}

$P$ value $=0.002$

Among the 68 ultrasonography positive cases for appendicitis, $65(95.5 \%)$ were also found to have positive features of appendicitis on histopathological examination and out of them $3(4.4 \%)$ were histologically negative.

Table 10: Analysis of ultrasonography in diagnosing acute appendicitis (histopathological findings being gold standard.

\begin{tabular}{|ll|}
\hline Ultrasonography & Percentage \\
\hline Sensitivity & $94.20 \%$ \\
\hline Specificity & $82.35 \%$ \\
\hline Positive predictive value & $95.58 \%$ \\
\hline Negative predictive value & $77.77 \%$ \\
\hline Diagnostic accuracy & $91.86 \%$ \\
\hline False positive error rate & $17.64 \%$ \\
\hline False negative error rate & $5.79 \%$ \\
\hline
\end{tabular}

In the 11 cases where ultrasonography ruled out appendicitis, out of them $4(22.22 \%)$ were histologically positive and $14(77.77 \%)$ were negative. 
In the present study ultrasonography had a sensitivity of $94.20 \%$ specificity of $82.35 \%$, positive predictive value of $95.58 \%$, negative predictive value of $77.77 \%$, diagnostic accuracy of $91.86 \%$, false positive error rate of $17.64 \%$ and a false negative error rate of $5.79 \%$.

Table 11: Comparison of modified Alvarado score and ultrasonography in diagnosis of acute appendicitis.

\begin{tabular}{|lll|ll|}
\hline \multirow{2}{*}{$\begin{array}{l}\text { Modified } \\
\text { Alvarado Score }\end{array}$} & \multicolumn{3}{c|}{ Positive } & \multicolumn{2}{l|}{ Negative } \\
\cline { 2 - 5 } & No. & $\%$ & No. & $\%$ \\
\hline$\geq 7$ ( Positive) & 48 & $94.11 \%$ & 3 & $5.90 \%$ \\
\hline$\leq 6$ (Negative) & 20 & $45.45 \%$ & 24 & $54.54 \%$ \\
\hline
\end{tabular}

$\mathrm{P}$ value $<0.0001$

In our study out of 51 modified alvarado score positive cases, $48(94.11 \%)$ were also positive on ultrasonography and $3(5.90 \%)$ were negative. Whereas in the remaining modified alvarado score negative cases 20 (45.45\%) were positive on ultrasonography.

Table 12: Comparison between modified Alvarado score, ultrasonography and histopathological findings.

\begin{tabular}{|c|c|c|c|c|}
\hline & \multicolumn{4}{|c|}{ Histopathological examination } \\
\hline & \multicolumn{2}{|c|}{ Positive } & \multicolumn{2}{|c|}{ Negative } \\
\hline & No. & $\%$ & No. & $\%$ \\
\hline $\begin{array}{l}\text { USG \& Mod Alvarado } \\
\text { Score Both -Ve }\end{array}$ & 4 & $25 \%$ & 12 & $75 \%$ \\
\hline $\begin{array}{l}\text { MOD Alvarado Score } \\
+\mathrm{Ve} \& \text { Usg - Ve }\end{array}$ & 1 & $33 \%$ & 2 & $67 \%$ \\
\hline $\begin{array}{l}\text { MOD Alvarado Score } \\
- \text {-Ve \& Usg }+ \text { Ve }\end{array}$ & 16 & $84.20 \%$ & 3 & $\begin{array}{l}15.80 \\
\%\end{array}$ \\
\hline $\begin{array}{l}\text { MOD Alvarado Score } \\
+ \text { Ve \& Usg + Ve }\end{array}$ & 48 & $100 \%$ & 0 & $0 \%$ \\
\hline
\end{tabular}

Table number 12 shows that when modified alvarado score and ultrasonography are combined together and both are positive sensitivity of diagnosing acute appendicitis is $100 \%$ in this study.

\section{DISCUSSION}

It is difficult to make confirm diagnosis of acute appendicitis, as there are many variable presentations of the disease. History and clinical examination help in diagnosis but even then there are different possibilities. The surgeon is the best person who can decide the best management and the more experienced is the surgeon, higher will be the diagnostic accuracy. But the junior surgeon has to make the initial assessment and decision to operate or not. So there is need of a complementary aid in difficult decision. In past few years various scoring systems have been designed to aid the diagnosis of acute appendicitis. The Alvarado score is simple scoring system that can be instituted easily. It was later modified by Kalen who then proposed the modified Alvarado scoring system. When the results of our study were compared with other standard studies sensitivity, specificity, positive predictive value and negative predictive value are comparable with these standard studies. In a study conducted by Ahmed et al, 98\% of patients with Alvarado score of at least 7 had evidence of acute appendicitis on histopathology with PPV of 98.1. The study of Horzic et al, documented $100 \%$ PPV with a score of at least 7 in the diagnosis of acute appendicitis in female individuals. ${ }^{5}$

The study of Hizbullah et al, documented PPV of $85 \%$ at a score of at least 7 . However, in another study conducted by Ikramullah et al, PPV was found to be $83.5 \%$ in adults. In the current study, the PPV was $87.5 \%$ at a score of at least 7 , which is comparable with the previous results. ${ }^{6,7}$ In the current study, at the cutoff point modified Alvarado score of at least 7; the sensitivity was $93.33 \%$, which is comparable with the results of Muzaffaruddin and Amer in their respective studies. Another study conducted by Pruekprasert et al, reported sensitivity of $79 \%$ at a score of at least $7 .^{8,9}$

The overall specificity of the test at the score of at least 7 was $52.94 \%$ (62.5\% for male individuals and $44.44 \%$ for female individuals), which is comparable with the results of a study conducted by Pouget-Baudry et al. that showed overall specificity of $58.18 \% .^{10}$ In the study of Ahmed et al, negative appendectomy at the score of at least 7 was $13.3 \%$ with presence of other pathology for the symptoms, whereas in a study by Malik and Sheikh negative appendectomy rate was $11 \%$; however, in the current study, negative appendectomy rate was $12.5 \%$ at the cut off value of modified Alvarado score of at least 7, which was comparable with the results of the other studies. $^{4,11}$

Therefore, modified Alvarado score is a useful tool and helps in clinical decision making especially when ultrasonography is unavailable. As imaging technique is comparatively expensive in India, scoring system should be used in selection of patients for further work-up. Ultrasound is unnecessary when ones degree of clinical suspicious is high. However the additional information provided by ultrasound does improve diagnostic accuracy in case of negative or equivocal modified Alvarado score. Both ultrasonography and modified Alvarado scoring system have similar false positive rates. When both modalities were positive the sensitivity was found to be $100 \%$ and thus can decrease negative appendectomies. Thus this study goes on to prove the adjunct value of modified Alvarado scoring system and ultrasonography in suspected cases of acute appendicitis. Thus, using both parameters increases the diagnostic accuracy of acute appendicitis and reduces negative appendectomies.

\section{CONCLUSION}

Acute appendicitis is one of the most common acute abdominal conditions requiring emergency surgery and its diagnosis remains challenging. In our study out of 86 
patients $69.76 \%$ were male and $30.24 \%$ were female Maximum incidence in adult age group seen in 20-40 years $(67 \%)$ Incidence after 50 years of age is very less (4.65\%). In our study out of 51 modified Alvarado score positive cases, $49(96 \%)$ were histologically positive and $2(4 \%)$ were negative. Whereas among remaining 35 modified Alvarado score negative cases only 20 (57.14\%) were histologically positive with a $\mathrm{p}$ value $<0.0001$. Among the 68 ultrasonography positive cases for appendicitis, $65(95.5 \%)$ were also found to have positive features of appendicitis on histopathologically examination and out of them $3(4.4 \%)$ were histologically negative. Whereas among 18 cases where ultrasonography ruled out appendicitis, out of them 4 (22.22\%) were histologically positive and 14 (77.77\%) were negative with a significant $\mathrm{p}$ value of 0.002 .

In this study modified Alvarado score had a sensitivity of $71.01 \%$, specificity of $88.2 \%$, positive predictive value of $96.07 \%$, negative predictive value of $42.85 \%$, diagnostic accuracy of $74.41 \%$, and false positive error rate of $11.76 \%$ and a false negative error rate of $28.98 \%$. While ultrasonography had a sensitivity of $94.20 \%$ specificity of $82.35 \%$, positive predictive value of $95.58 \%$, negative predictive value of $77.77 \%$, diagnostic accuracy of $91.86 \%$, false positive error rate of $17.64 \%$ and a false negative error rate of $5.79 \%$.

When modified Alvarado score and ultrasonography are combined together and both are positive sensitivity of diagnosing acute appendicitis is $100 \%$ in this study. Although ultrasonography is method used frequently for diagnosis of acute appendicitis, using modified Alvarado score can also be a useful tool in clinical decisionmaking. As modified Alvarado score is simple, easily applicable in peripheral hospitals where back up facilities are sparse. It can be useful for junior doctors in patients of abdominal emergencies. Although it is not mandatory to get an ultrasonography done when there is high clinical suspicion of acute appendicitis but additional information provided by ultrasonography is very useful in borderline cases. Thus we finally conclude that incorporation of modified Alvarado scoring system for establishment of diagnosis in cases of suspected acute appendicitis surely provides higher accuracy of diagnosing acute appendicitis and helps in decreasing negative appendectomies.
Funding: No funding sources Conflict of interest: None declared

Ethical approval: The study was approved by the institutional ethics committee

\section{REFERENCES}

1. Fitz RH. Perforating inflammation of the vermiform appendix: with special reference to its early diagnosis and treatment. Am J Med Sci. 1886;92:321-46.

2. Hoffmann J, Rasmussen OO. Aids in the diagnosis of acute appendicitis Br S Surg. 1989;76(8):774-9.

3. Borushok KF, Jeffrey RB, Laing FC, Townsend RR. Sonographic diagnosis of perforation in patients with acute appendicitis. AJR Am J Roentgenol. 1990;154:275-8.

4. Ahmed AM, Vohra LM, Khaliq T, Lehri AA. Diagnostic accuracy of Alvarado score in the diagnosis of acute appendicitis. Pak J Med Sci. 2009;25:118-21.

5. Horzic M, Salamon A, Kopljar M, Skupnjak M, Cupurdija K, Vanjak D. Analysis of scores in diagnosis of acute appendicitis in women. Coll Antropol. 2005;29:133-8.

6. Jan H, Khan J. Evaluation of modified Alvarado score in the diagnosis of acute appendicitis. Pak J Surg. 2007;23:248-50.

7. Khan I, Rehman A. Application of Alvarado scoring system in diagnosis of acute appendicitis. J Ayub Med Coll Abbottabad. 2005;17:41-4.

8. Sadiq M, Amir S. Efficacy of modified Alvarado scoring system in the diagnosis of acute appendicitis. JPMI. 2002;16:72-7.

9. Pruekprasert P, Maipang T, Geater A, Apakupakul $\mathrm{N}$, Ksuntigij P. Accuracy in diagnosis of acute appendicitis by comparing serum $\mathrm{C}$-reactive protein measurements, Alvarado score and clinical impression of surgeons. $\mathrm{J}$ Med Assoc Thai. 2004;87:296-303.

10. Pouget-Baudry Y, Mucci S, Eyssartier E, GuesdonPortes A, Lada P, Casa C, et al. The use of the Alvarado score in the management of right lower quadrant abdominal pain in the adult. J Visc Surg. 2010;147:40-4.

11. Malik KA, Sheikh MR. Role of modified Alvarado score in acute appendicitis. Pak J Surg. 2007;23:251-4.

Cite this article as: Patel V, Kela M, Prasad S, Gautam AS, Gupta M. Evaluation of modified Alvarado scoring system in diagnosis of acute appendicitis - a prospective study. Int Surg J 2016;3:621-5. 